\title{
SELECTIONS FROM THE TABLE OF LIFE MEMBERSHIP FEES
}

(Rates for other years may be obtained from the Treasurer.)

\begin{tabular}{ccc} 
Age & \multicolumn{2}{c}{ Fee } \\
$\mathbf{2 5}$ & $\ldots \ldots \ldots \ldots 143.37$ \\
$\mathbf{3 0}$ & $\ldots \ldots \ldots \ldots$ & $\mathbf{1 3 7 . 9 3}$ \\
$\mathbf{3 5}$ & $\ldots \ldots \ldots \ldots$ & 131.48 \\
40 & $\ldots \ldots \ldots \ldots$ & 123.88 \\
45 & $\ldots \ldots \ldots \ldots$ & 115.13 \\
$\mathbf{5 0}$ & $\ldots \ldots \ldots \ldots$ & $\mathbf{1 0 5 . 2 4}$
\end{tabular}

\begin{tabular}{|c|c|}
\hline Age & Fee \\
\hline 55 & $\ldots$ \\
\hline 60 & $\ldots 8$ \\
\hline 65 & $\ldots 70$ \\
\hline 70 & $\ldots \ldots \ldots$ \\
\hline $\begin{array}{l}75 \\
80\end{array}$ & $\ldots \ldots \ldots \ldots \ldots$ \\
\hline
\end{tabular}

\section{DIRECTORY}

The American Mathematical Society has an office in the Physics Building of Columbia University; the mail address of this office is 501 West 116th Street, New York, N. Y. Any officer of the Society may be addressed there.

The Secretary of the Society is Dean R. G. D. Richardson, Brown University, Providence, R. I.

Associate Secretaries are

Professor Arnold Dresden, Swarthmore College, Swarthmore, Pa.;

Professor M. H .Ingraham, University of Wisconsin, Madison, Wis.;

Dean T. M. Putnam, University of California, Berkeley, Calif. N. Y.

The Treasurer is Professor G. W. Mullins, Columbia University, New York,

The Librarian is Professor R. C. Archibald, Brown University, Providence, R. I.

The Editor-in-Chief of the Bulletin is Professor E. R. Hedrick, University of California at Los Angeles, Los Angeles, Calif.

The Clerk is Dr. Caroline E. Seely, 501 West 116th Street, New York, N. Y.

\section{PUBLICATIONS}

Bulletin of the American Mathematical Society.

Transactions of the American Mathematical Society.

Mathematical Papers of the Chicago Congress, 1893.

Evanston Colloquium Lectures, 1893, by Felix Klein.

\section{Colloquium Series}

Volume 1. The Boston Colloquium, by H. S. White, F. S. Woods, and E. B. Van Vleck. 1905.

Volume 2. The New Haven Colloquium. Out of print.

Volume 3. The Princeton Colloquium, by G. A. Bliss and E. Kasner. 1913.

Volume 4. The Madison Colloquium, by L. E. Dickson and W. F. Osgood. 1914.

Volume 5. The Cambridge Colloquium. Part I: Functionals and their Applications, by G. C. Evans. 1918. Part 2: Analysis Situs, by O. Veblen; out of print; a new edition is being prepared.

Volume 6. The Logarithmic Potential. Discontinuous Dirichlet and Neumann Problems, by G. C. Evans. 1927.

Volume 7. Algebraic Arithmetic, by E. T. Bell. 1927.

Volume 8. Non-Riemannian Geometry, by L. P. Eisenhart. 1927.

Volume 9. Dynamical Systems, by G. D. Birkhoff. 1927.

Volume 10. Algebraic Geometry and Theta Functions, by A. B. Coble. 1929.

Volume 11. The Theory of A pproximation, by D. Jackson. 1930.

Volume 12. Topology, by S. Lefschetz. In press. 